\title{
Ethyl Levulinate Obtained from Lignocellulosic Waste Material with Previous Delignification by Ultrasonic-Assisted Technique
}

\author{
Jorge Ernesto Solá-Pérez, Hugo Saldarriaga-Noreña, Mario Murillo-Tovar \\ Centro de Investigaciones Químicas, ICCBA, Universidad Autónoma del Estado de Morelos, Cuernavaca, México \\ Email: jsolaperez@uaem.mx
}

How to cite this paper: Solá-Pérez, J.E., Saldarriaga-Noreña, H. and Murillo-Tovar, M. (2017) Ethyl Levulinate Obtained from Lignocellulosic Waste Material with Previous Delignification by Ultrasonic-Assisted Technique. Journal of Agricultural Chemistry and Environment, 6, 93-103. https://doi.org/10.4236/jacen.2017.61006

Received: November 16, 2016

Accepted: February 21, 2017

Published: February 24, 2017

Copyright $\odot 2017$ by authors and Scientific Research Publishing Inc. This work is licensed under the Creative Commons Attribution International License (CC BY 4.0).

http://creativecommons.org/licenses/by/4.0/

\begin{abstract}
Ultrasound-assisted pretreatment under mild operating conditions has been investigated for intensification of delignification to facilitate the obtaining of ethyl levulinate from biomass. The effect of $\mathrm{pH}(2-12)$, temperature $\left(30^{\circ} \mathrm{C}\right.$ $\left.70^{\circ} \mathrm{C}\right)$ and pretreatment time $(0-120$ minutes $)$ has been studied for different biomass samples. The most favorable conditions were basic $\mathrm{pH}$, temperature of $70^{\circ} \mathrm{C}$ and pretreatment time of $2 \mathrm{~h}$, obtaining values of delignification near 80 percent. The ethyl levulinate is obtained in microwave directly via from samples before and after delignification and analyzed for GC-MS. The results evidenced better yields for the delignified samples.
\end{abstract}

\section{Keywords}

Ethyl Levulinate, Delignification, Wheat Straw, Sugarcane Bagasse, Maguey Bagasse

\section{Introduction}

Some environmental impacts have been widely discussed in recent years, and one of the main reasons has been the establishment of public policies aimed at ecological sustainability. Large amounts of lignocellulosic waste generated through forestal and agricultural practice, such as paper-pulp industries, timber industries and many agro-industries are generating serious environmental pollution problems. In this regard, the use of organic waste as a base for obtaining new substances or value-added chemical has opened the possibility of using biomass generated by various agro-industrial processes for the production of biofuels. Lignocellulosic biomass is a versatile renewable feedstock for biorefining of which the main constituents are the biopolymers cellulose, hemicellulose, and lignin. The efficient fractionation of lignocellulosic biomass into its main 
components, so that all fractions may be valorized, is a prerequisite for economic lignocellulosic biorefinery [1] [2]. In particular, the use of lignocellulosic agriculture and forestry residues for biorefineries is promising because of high availability, relatively low costs and no direct competition with food and feed production [3].

Most of the research on lignocellulosic residues focuses on chemical components for animal feed supplement, soil conditioners, fermentative production of metabolites of interest and generation of bio-energetics [4]. However, still we need further studies to obtain and/or develop new products, in order to seek new areas of application.

One of those products of interest is the ethyl levulinate, a compound used as a fuel additive [5] [6], improving combustion efficiency and decreasing the amount of emissions to the environment [5]; this substance is also used in the manufacture of some foods as emulsifier and cosmetics [7]. Obtaining ethyl levulinate from lignocellulosic waste is carried out mainly by two routes: the first from levulinic acid (indirect) obtained from the hydrolysis of the sugars in acidic medium and the second is direct; therefore, the acid hydrolysis of lignocellulosic material is performed in ethanolic medium, for the ethyl levulinate (Figure 1).

Most of the studies on obtaining ethyl levulinate had used waste directly without a prior chemical treatment, which is usually done frequently, primarily for obtaining bioethanol by enzyme [8] [9]. The pretreatment requires a higher consumption of reagents; it allows the removal of lignin. This would facilitate chemical reactions for the formation of ethyl levulinate and therefore a higher yield in the process.

(a)<smiles>CCOC(=O)CCC(C)=O</smiles><smiles>CC1(C(O)C(OC2C(CO)OC(O)C(O)C2O)OC2CCCCC2(O)O)CCCCO1</smiles>

(b)<smiles>CCOC(=O)CCC(C)=O</smiles>

Figure 1. General pathways to obtain ethyl levulinate, (a) indirect route and (b) direct route. 
Currently there are several biological, physical and chemical technologies for pretreatment of biomass such as use of enzymes [10] [11], ball mills, steam explosion, acids, alkalis [12], wet oxidation, among other [13]. Some of pretreatment methods including the use of acid, wet oxidation and the use of calcium oxide, the latter appear to be economically more feasible than other [14]. However, concern for the environment and the formation of enzymatic inhibitors during these processes are major obstacles that must be overcome [15].

Those pretreatment separates lignin from carbohydrates, which limits the accessibility of enzymes or chemicals to cellulose and hemicellulose. The main objective of pretreatment is to increase accessibility to cellulose and improve his digestibility. Each treatment (physical, biological, thermal and chemical processes) has a specific effect on different fractions of cellulose, hemicellulose and lignin [16].

The pretreatment processes for delignification more frequently used are acid hydrolysis, hydrothermal pretreatment, alkaline pretreatment microwave assisted, low-temperature pretreatment using mixtures of ethylene carbonate and ethylene glycol [17], assisted by cavitation [18] [19], mixtures of glycerol water [20], ethanol-water mixtures using carbon dioxide at high pressures [21], subsequent extraction with organic solvents at acidic pretreatment [11], hydrodynamic cavitation, microwave assisted extraction [22] [23] between others [14] [24].

Since so far, only some of these methods has shown high efficiencies for poor performance and intensive energy and capital cost. In this study we propose some experimental optimizations that will generate higher content of lignocellulosic material using a pretreatment for delignification before obtaining the ethyl levulinate. Delignification by ultrasonic-assisted is a good option, because of the cavitation produced, the bonds must be broken more easily, occurring the reaction faster and with lower consumption of reagents.

\section{Experimental}

\subsection{Materials and Reagent}

Sulfuric acid (ACS, CIVEQ), Ethanol (ACS, HYCEL), Ethyl Levulinate (ALDRICH), Sodium Hydroxyde (REASOL), Hydrochloric Acid (ACS, CIVEQ).

\subsection{Sample}

Lignocellulosic residues used were obtained from different places in the state of Morelos; wheat straw (Triticum aestivum. L.) was provided by the Center for Biological Research of the UAEM; maguey bagasse (Agave tequilana) in Miacatlan and sugarcane bagasse (Saccharum lubridatium) by Emiliano Zapata sugar mill in Zacatepec (Figure 2).

The samples were dried at $105^{\circ} \mathrm{C}$ to constant weight, then crushed with a blade mill and stored at room temperature in ziploc bag.

\subsection{Ultrasound Assisted Delignification}

The delignification experiments were performed in ultrasonic bath (SB-5200 


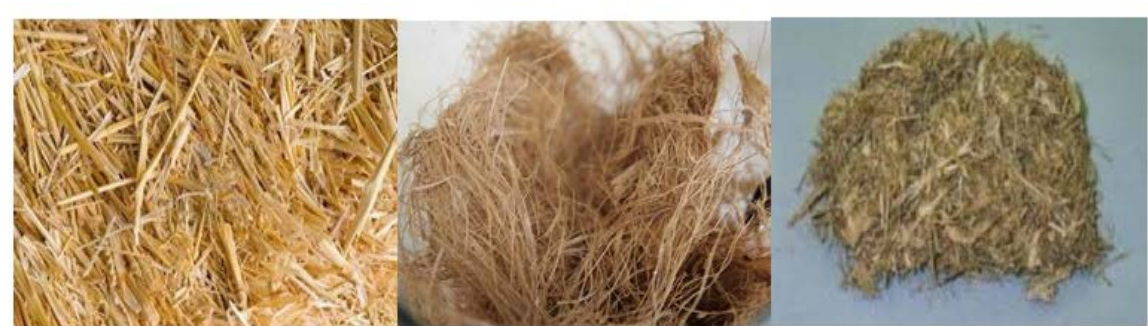

(a)

(b)

(c)

Figure 2. Lignocellulosic residues: (a) wheat straw; (b) sugarcane bagasse and (c) maguey bagasse

DTN) and all experiments were conducted in a $150 \mathrm{ml}$ glass balloon with ratio of 1:20 (lignocellulosic mass: solution volume) at reflux using five level and three variables. Assessment of the delignification procedure was done for the following independent variables: (1) $\mathrm{pH}$, (2) temperature and (3) reaction time.

\subsection{Total Lignin Quantification}

The chemical characterization of the pulp was obtained by determining the quantity of acid-insoluble lignin (the Klason lignin method) according to the Technical Association of the Pulp and Paper Industry (TAPPI) standard method T222 om-02. In the Klason method, the sample is hydrolyzed by a sulfuric acid solution, and the acid insoluble lignin is separated from the hydrolysate through filtration. The acid-insoluble lignin was oven-dried at $105^{\circ} \mathrm{C}$ and weighed.

\subsection{Ethyl Levulinate Production}

The experiments were carried out with the samples obtained from delignification process, reacted with acidified ethanol in a microwave equipment with a power of 100 watts to reflux for 10 minutes, at a temperature of $70^{\circ} \mathrm{C}$. The samples were filtered and the ethanol extract was concentrated on a rotary evaporator. Finally the concentrated samples were extracted for liquid- liquid extraction with toluene before analysis.

\subsection{Ethyl Levulinate Analysis}

Ethyl levulinate soluble in toluene was determined on a GC (Agilent 6890 instrument) equipped with mass selective detector (Agilent 5973) by impact electronic $70 \mathrm{eV}$. The sample was injected $1 \mu \mathrm{l}$ and separated on HP-5MS capillary column $(30.0 \mathrm{~m} \times 0.25 \mathrm{~mm} \times 0.25 \mu \mathrm{m})$ and programmed temperature configured ranged of $45^{\circ} \mathrm{C}$ to $285^{\circ} \mathrm{C}$ with helium as the carrier gas. Because quantification was performed a calibration curve in a range of $0.3-4.5 \mathrm{mg} / \mathrm{ml}$.

\section{Results and Discussion}

\subsection{Effects of $\mathrm{pH}$}

The delignification process is affected by different factors, among which is the $\mathrm{pH}$ for hydrolysis of lignin. Experiments were performed changing the $\mathrm{pH}$ from 
2 to 12 (Figure 3). The standard deviations for the different samples are 0.066 for wheat straw, 0.219 sugarcane bagasse and 0.078 for maguey bagasse.

In the case of wheat straw, in a $\mathrm{pH}$ range of 2.0-5.0, the results indicated no great difference to the concentration of extracted lignin. From $\mathrm{pH} 5.0$, begins to increase efficiency in the extraction of lignin, reaching maximum efficiency at a $\mathrm{pH}$ of 12.0, that behavior can probably be explained by the complex structure of lignin and reactions of rupture of the links occur under these conditions.

Lignin reactions under acidic conditions when light (concentrations $<1.0 \mathrm{M}$ ) results in an autocatalytic break of bonds formed between lignin and hemicellulose. The most important reaction via during acidolysis lignin is the breaking of bonds $\beta$-O- 4 (Figure 4 and Figure 5 ). This cleavage reaction has been described by several authors [25]. Lignin units are often connected by $\beta$-O- 4 bonds in $\beta$ position. During the reaction of cleaved these bonds in the $\beta$ position, initially is formed the intermediary cation, benzyl and type enol-ether substructure. The $\beta$-O- 4 bond is then hydrolyzed to link a new unit of phenolic lignin and substructure Hibbert's ketone (route A).

Another proposed route also involves the breakdown of the $\beta$-O-4 bonds, generating formaldehyde from the $\gamma$ position and another type enol-ether structure, is described in Figure 4. It has been reported that these reactions occur in acid medium at elevated temperatures. Because of this and the type of acid used that influences the formation of the compounds formed during the process [25] is likely that low yields are observed in the delignification process in general.

Another cleavage reaction of lignin which occurs in acidic medium is the breaking of bonds $\alpha$-ether. Similar to the links $\beta$-ethers, $\alpha$-aryl ethers are rapidly hydrolysed being responsible for the formation of lignin components of low weight molecular.

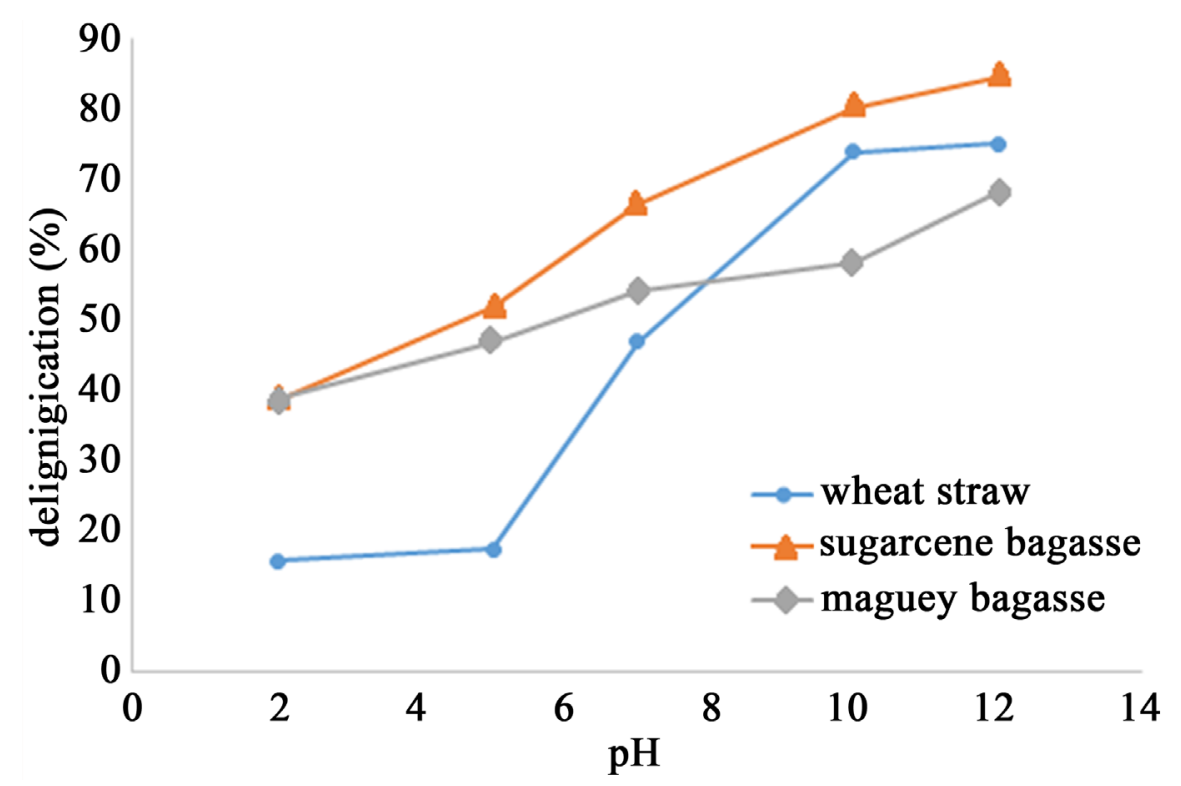

Figure 3. Percentage of delignification in function of $\mathrm{pH}$ for different treated samples to reaction time $30 \mathrm{~min}$ and temperature $40^{\circ} \mathrm{C}$. 
I. Esolib Perezetal.

$$
\begin{aligned}
& b^{2} y^{2} \\
& \text { द }
\end{aligned}
$$

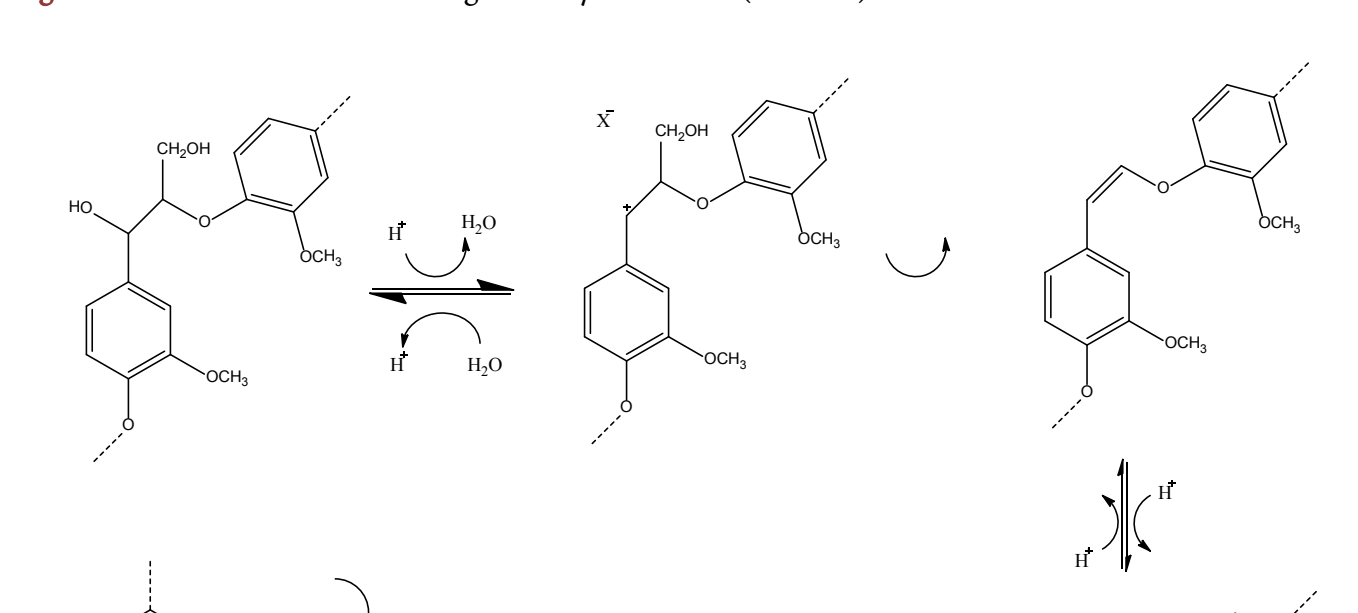

$$
\begin{aligned}
& \text { \& }
\end{aligned}
$$


Few treatments in obtaining fuel additives from biomass using high $\mathrm{pH}(9.0-$ 12.0). Frequently for pulping lignin obtaining, is used alkaline reaction at high temperatures. The $\mathrm{C}-\mathrm{C}$ bonds are relatively stable under these conditions, while the $\mathrm{C}-\mathrm{O}$ bonds are easier to break.

Ruptures $\alpha$-ethers bonds occur when have free $\mathrm{OH}$ phenolic groups present in the para position relative to the chain Propyl, facilitating the formation of the intermediary methyl-quinone during the reaction. The $\alpha$-ethers bonds nonphenolic can also be broken if the $\mathrm{OH}$ group is adjacent to the $\beta$ position forming as intermediary an epoxide. The breaking of bonds $\beta$-O-4 occurs if there is $\mathrm{OH}$ group or carbonyl adjacent to the $\alpha$ and $\gamma$ position.

Overall, the results for lignin extracted from samples indicated that the percentage of delignification, obtained under basic $\mathrm{pH}$ values, were higher than those obtained by acid conditions, probably the breaks of the $\alpha$ and $\beta$ bonds are favored; indicating that the structure of the lignin in the three samples are $\mathrm{OH}$ groups in para position or adjacent to $\alpha$ and $\gamma$ position. Some methods have used acid hydrolysis pretreatment [26], however when the acid hydrolysis is performed also react polysaccharides [27] which are the precursors for obtaining ethyl levulinate. While the use of ultrasound to basic $\mathrm{pH}$ favors the formation of peroxydril radical is very reactive, also it increases the solubility of the hydrolysis products of lignin compounds by forming charge and decreases the degradation of cellulose, latter promotes an increase of performance in process obtaining ethyl levulinate.

\subsection{Effect of Pretreatment Time}

To study how reaction time influence in the delignification process for ultrasound assisted, was analyzed lignin extracted variation versus reaction time for different waste (Figure 6).

The effect of pretreatment time in the extraction of lignin in the solid residue, indicates that in the first 60 minutes of reaction, the greatest efficiency is achie-

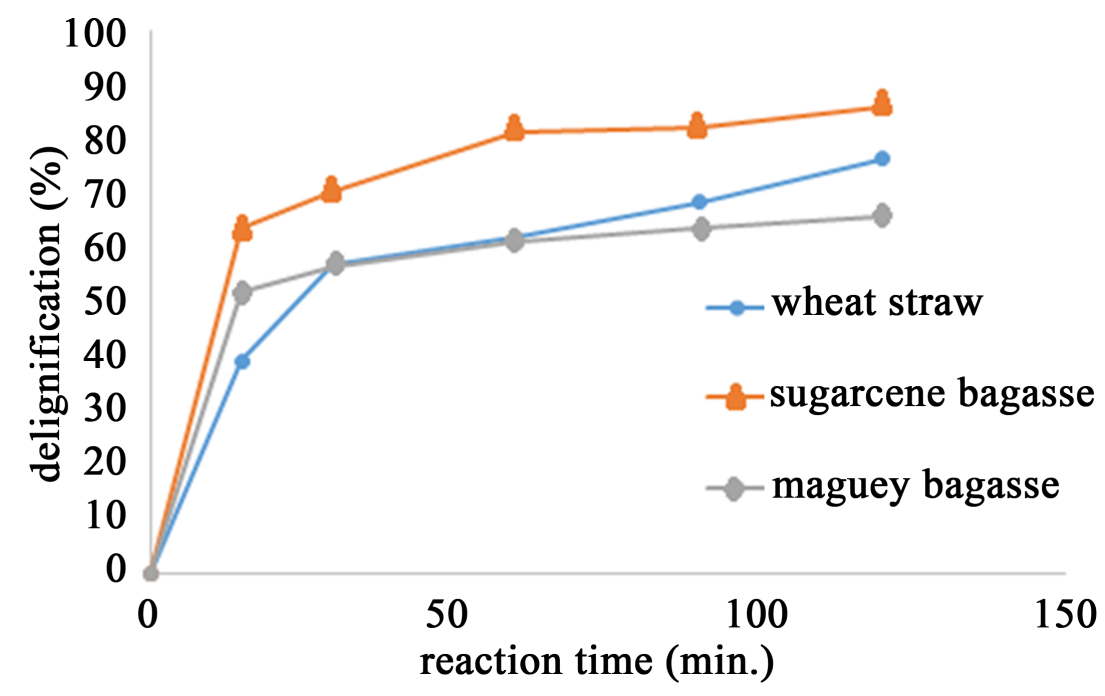

Figure 6. Percentage delignification samples versus reaction time to $\mathrm{pH}=7.0$ and $40^{\circ} \mathrm{C}$. 
ved in removal of lignin, studied for three residues, it is the sugarcane bagasse which introduced greater efficiency; while wheat straw and maguey bagasse showed the same behavior. After 60 minutes, was not observed a significant change in efficiency, probably it is indicating that the balance between the compounds of lignin degradation dissolved in solution and those formed on the surface of the residue is determined by saturation of the solution.

\subsection{Effect of Pretreatment Temperature}

The temperature for the pretreatment of the samples was varied from $30^{\circ} \mathrm{C}$ to $70^{\circ} \mathrm{C}$ (Figure 7). However the behavior depends on the sample, for the wheat straw is observed increase between $40^{\circ} \mathrm{C}-60^{\circ} \mathrm{C}$, in the cane bagasse it is between $30^{\circ} \mathrm{C}-40^{\circ} \mathrm{C}$ decreasing to temperatures higher up to $60^{\circ} \mathrm{C}$, in the maguey bagasse the variation is observed between $30^{\circ} \mathrm{C}$ and $40^{\circ} \mathrm{C}$; this is due to the possible different energies of the transition states.

As expected with increasing temperature concentration lignin extracted at the same reaction time increases, because more energy is supplied facilitating the breaking of bonds and increasing the solubility of the compounds formed in the liquid medium; in general the rate at which the reaction occurs, increases until it reaches a maximum that is likely to increase the number of molecules with enough energy to pass the transition state to products.

The observed results demonstrate for the three residues studied, than the greatest efficiency of delignification with $60 \%-85 \%$ was obtained to $60^{\circ} \mathrm{C}$ $70^{\circ} \mathrm{C}$. These results are consistent with those found in other studies, for example (Iskalieva 2012) reported percentages up to $78 \%$ for wheat straw residues using ultrasound assisted, meanwhile (Pasquini 2005) found percentages close to $88 \%$

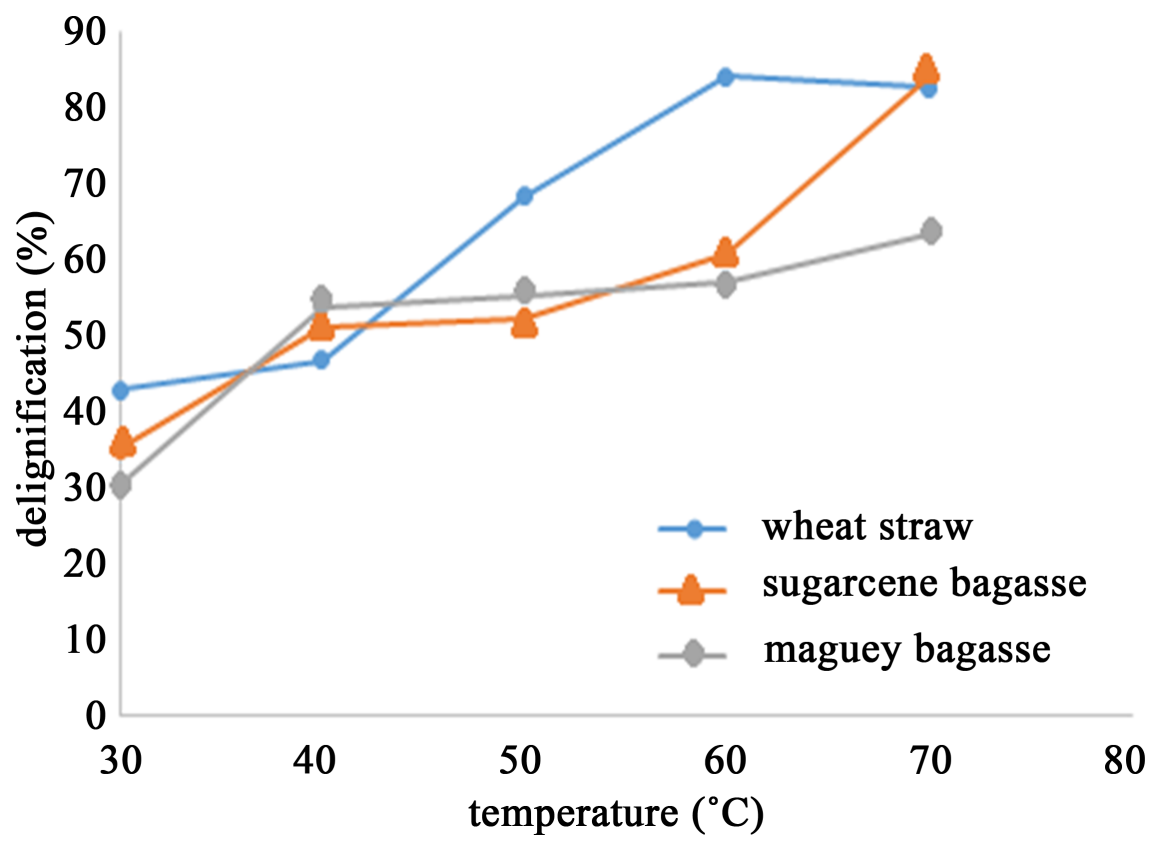

Figure 7. Percent delignification in function of temperature to $\mathrm{pH} 7.0$ and reaction time $30 \mathrm{~min}$. 
using a pressurized fluid system with carbon dioxide, while Monteil-Rivera reported $91 \%$ using microwave assisted extraction.

\subsection{Effect of Delignification for Obtaining Ethyl Levulinate}

The synthesis of the ethyl levulinate assisted microwave is used due to its advantages in terms of saving time and energy. For determining the amount of ethyl levulinate obtained, the organic extracts were concentrated on a rotary evaporator to remove ethanol excess, then extraction with toluene was performed to separate the ethyl levulinate from the aqueous extract. The organic concentrated extract was analyzed by gas chromatography coupled to mass spectrometry. Figure 8 shows the concentration of ethyl levulinate obtained from the calibration curve.

The best results were obtained in the samples that were previously delignified. The concentrations of ethyl levulinate were 3 to 1 frequency better for delignified samples, regarding was not performed prior treatment, obtaining better results in wheat straw, and lesser grade in sugarcane bagasse and maguey bagasse.

\section{Conclusions}

When the delignification process is assisted by ultrasonic, the best results are obtained for alkaline, $\mathrm{pH}$ favored likely the formation of peroxydril radicals, and also under these conditions, the phenoxy radical is an oxidized form of lignin and is much more hydrophilic than this, allowing the formed lignin to be removed more easily. The temperature favored the delignification increases because it increases the kinetic energy and gets more quickly to the formation of the activated complex, obtaining the best results for the three samples between $60^{\circ} \mathrm{C}$ and $70^{\circ} \mathrm{C}$. For this process, using other methods are required long time intervals, however, the method assisted by ultrasound reaches a maximum extraction when the process is in 1 hour. Therefore, ultrasonically assisted delignification allows us to obtain good delignification at relatively low temperatures $\left(60^{\circ} \mathrm{C}\right)$ in an alkaline medium and the shortest reaction time, implying lower power consumption than other methods. The process of delignification also

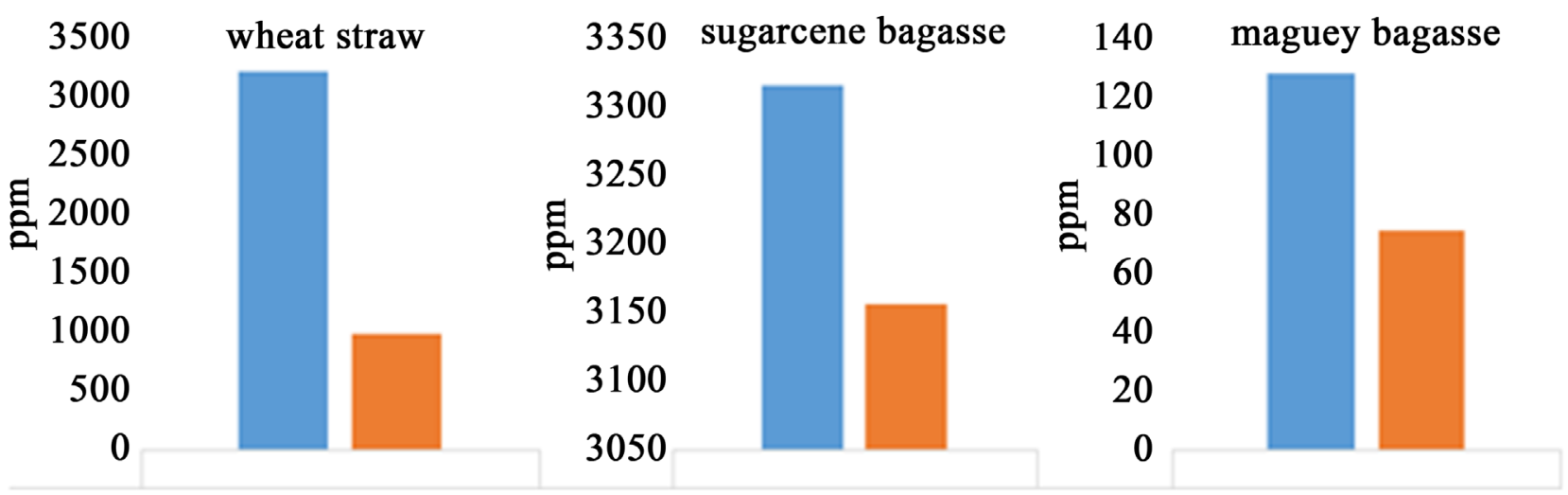

Figure 8. Relationship between the concentration of ethyl levulinate in ( $\mathrm{ppm}$ ) obtained by microwave, and the treated and untreated samples. 
favors obtaining ethyl levulinate, as the lignin has been removed completely or partially, allowing the reagents acting more directly on the holocellulose. In all cases they were observed a difference between the untreated and delignified samples.

\section{References}

[1] Le, D.M. (2014) Biorefining of Wheat Straw: Accounting for the Distribution of Mineral Elements in Pretreated Biomass by an Extended Pretreatment-Severity Equation. Biotechnology for Biofuels, 7, 1-13. https://doi.org/10.1186/s13068-014-0141-7

[2] Huijgen, W.J.J. (2012) Fractionation of Wheat Straw by Prehydrolysis, Organosolv Delignification and Enzymatic Hydrolysis for Production of Sugars and Lignin. Bioresource Technology, 114, 389-398. https://doi.org/10.1016/j.biortech.2012.02.143

[3] Briones, R. (2012) Valorization of Some Lignocellulosic Agro-Industrial Residues to Obtain Biopolyols. Journal of Chemical Technology and Biotechnology, 87, 244249. https://doi.org/10.1002/jctb.2706

[4] Saval, S. (2012) Aprovechamiento de Residuos Agroindustriales: Pasado, Presente y Futuro. BioTecnología, 16.

[5] Joshi, H. (2011) Ethyl Levulinate: A Potential Bio-Based Diluent for Biodiesel Which Improves Cold Flow Properties. Biomass and Bioenergy, 35, 3262-3266. https://doi.org/10.1016/j.biombioe.2011.04.020

[6] Yadav, G.D. (2014) Synthesis of Ethyl Levulinate as Fuel Additives Using Heterogeneous Solid Superacidic Catalysts: Efficacy and Kinetic Modeling. Chemical Engineering Journal, 243, 556-563. https://doi.org/10.1016/j.cej.2014.01.013

[7] Saravanamurugan, S. (2011) Conversion of Mono- and Disaccharides to Ethyl Levulinate and Ethyl Pyranoside with Sulfonic Acid-Functionalized Ionic Liquids. ChemSusChem, 4, 723-726. https://doi.org/10.1002/cssc.201100137

[8] Ruiz, H.A. (2012) Bioethanol Production from Hydrothermal Pretreated Wheat Straw by a Flocculating Saccharomyces Cerevisiae Strain-Effect of Process Conditions. Fuel, 95, 528-536. https://doi.org/10.1016/j.fuel.2011.10.060

[9] Govumoni, S.P. (2013) Evaluation of Pretreatment Methods for Enzymatic Saccharification of Wheat Straw for Bioethanol Production. Carbohydrate Polymers, 91, 646-650. https://doi.org/10.1016/j.carbpol.2012.08.019

[10] Hansen, M.A.T. (2011) Pretreatment and Enzymatic Hydrolysis of Wheat Straw (Triticum aestivum L.) - The Impact of Lignin Relocation and Plant Tissues on Enzymatic Accessibility. Bioresource Technology, 102, 2804-2811.

[11] Yang, Q. (2012) Pretreatment of Agave americana Stalk for Enzymatic Saccharification. Bioresource Technology, 126, 336-340. https://doi.org/10.1016/j.biortech.2012.10.018

[12] McIntosh, S. (2011) Optimisation of Dilute Alkaline Pretreatment for Enzymatic Saccharification of Wheat Straw. Biomass and Bioenergy, 35, 3094-3103. https://doi.org/10.1016/j.biombioe.2011.04.018

[13] Chen, M. (2015) Optimisation of Ultrasonic-Assisted Extraction of Phenolic Compounds, Antioxidants, and Anthocyanins from Sugar Beet Molasses. Food Chemistry, 172, 543-550. https://doi.org/10.1016/j.foodchem.2014.09.110

[14] Guragain, Y.N. (2011) Comparison of Some New Pretreatment Methods for Second Generation Bioethanol Production from Wheat Straw and Water Hyacinth. Biore- 
source Technology, 102, 4416-4424. https://doi.org/10.1016/j.biortech.2010.11.125

[15] Soares, M.L. (2013) Influence of the Alkaline Delignification on the Simultaneous Saccharification and Fermentation (SSF) of Sugar Cane Bagasse. Bioresource Technology, 147, 645-648. https://doi.org/10.1016/j.biortech.2013.08.103

[16] Yang, B. (2008) Pretreatment: The Key to Unlocking Low-Cost Cellulosic Ethanol. Biofuels, Bioproducts and Biorefining, 2, 26-40. https://doi.org/10.1002/bbb.49

[17] Zhang, Z. (2013) Low Temperature Pretreatment of Sugarcane Bagasse at Atmospheric Pressure Using Mixtures of Ethylene Carbonate and Ethylene Glycol. Green Chemistry, 15, 255-264. https://doi.org/10.1039/C2GC36323B

[18] Iskalieva, A. (2012) Cavitation Assisted Delignification of Wheat Straw: A Review. Ultrasonics Sonochemistry, 19, 984-993. https://doi.org/10.1016/j.ultsonch.2012.02.007

[19] Badve, M.P. (2014) Hydrodynamic Cavitation as a Novel Approach for delignification of Wheat Straw for Paper Manufacturing. Ultrasonics Sonochemistry, 21, 162-168. https://doi.org/10.1016/j.ultsonch.2013.07.006

[20] Novo, L.P. (2011) Delignification of Sugarcane Bagasse Using Glycerol-Water Mixtures to Produce Pulps for Saccharification. Bioresource Technology, 102, 1004010046. https://doi.org/10.1016/j.biortech.2011.08.050

[21] Pasquini, D. (2005) Extraction of Lignin from Sugar Cane Bagasse and Pinus taeda Wood Chips Using Ethanol-Water Mixtures and Carbon Dioxide at High Pressures. Journal of Supercritical Fluids, 36, 31-39. https://doi.org/10.1016/j.supflu.2005.03.004

[22] Singh, A. (2012) Enzymatic Hydrolysis Optimization of Microwave Alkali Pretreated Wheat Straw and Ethanol Production by Yeast. Bioresource Technology, 108, 94-101. https://doi.org/10.1016/j.biortech.2011.12.084

[23] Monteil-Rivera, F. (2012) Microwave-Assisted Extraction of Lignin from Triticale Straw: Optimization and Microwave Effects. Bioresource Technology, 104, 775-782. https://doi.org/10.1016/j.biortech.2011.11.079

[24] Fu, D. (2011) Optimization of Processing Conditions for the Pretreatment of Wheat Straw Using Aqueous Ionic Liquid. Bioresource Technology, 102, 8003-8010. https://doi.org/10.1016/j.biortech.2011.06.023

[25] Santos, R.B. (2013) Wood Based Lignin Reactions Important to the Biorefinery and Pulp and Paper Industries. Bioresources, 8, 1456-1477. https://doi.org/10.15376/biores.8.1.1456-1477

[26] Guerra-Rodríguez, E. (2012) Acid Hydrolysis of Wheat Straw: A Kinetic Study. Biomass and Bioenergy, 36, 346-355. https://doi.org/10.1016/j.biombioe.2011.11.005

[27] Zhang, Z. (2013) Pretreatment of Sugarcane Bagasse by Acidified Aqueous Polyol Solutions. Cellulose, 20, 3179-3190. https://doi.org/10.1007/s10570-013-0068-3 
Submit or recommend next manuscript to SCIRP and we will provide best service for you:

Accepting pre-submission inquiries through Email, Facebook, LinkedIn, Twitter, etc. A wide selection of journals (inclusive of 9 subjects, more than 200 journals)

Providing 24-hour high-quality service

User-friendly online submission system

Fair and swift peer-review system

Efficient typesetting and proofreading procedure

Display of the result of downloads and visits, as well as the number of cited articles Maximum dissemination of your research work

Submit your manuscript at: http://papersubmission.scirp.org/

Or contact jacen@scirp.org 